\title{
Design para a Sustentabilidade - um conceito interdisciplinar em construção
}

\author{
Design for Sustainability - an interdisciplinary concept in construction
}

\author{
Cavalcante, Ana Luisa Boavista Lustosa; Doutoranda; \\ Universidade Federal de Santa Catarina - UFSC \\ anaboavista@uel.br \\ Preto, Seila Cibele Sitta; Mestranda; \\ Universidade Federal de Santa Catarina - UFSC \\ cibelesittap@gmail.com \\ Pereira, Francisco Antônio Fialho; Doutor; \\ Universidade Federal de Santa Catarina - UFSC \\ fapfialho@gmail.com \\ Figueiredo, Luiz Fernando Gonçalves de ;Doutor \\ Universidade Federal de Santa Catarina - UFSC \\ Iff@cce.ufsc.br
}

\begin{abstract}
RESUMO
O Design se propõe a desenvolver produtos e serviços mediante necessidades humanas. Dentro dos princípios contemporâneos dessa atividade têm-se as dimensões do Desenvolvimento Sustentável, a inovação e o bem-estar social. O Desenvolvimento Sustentável possui conceitos provenientes de várias disciplinas e conhecimentos humanos. Desse modo, este artigo visa sistematizar o conceito de Design para a Sustentabilidade, evidenciando sua interdisciplinaridade. Para tanto, realizou-se uma pesquisa bibliográfica para a sistematização das informações levantadas em um mapa conceitual.
\end{abstract}

Palavras-chave: Design; Desenvolvimento Sustentável; interdisciplinaridade.

\begin{abstract}
The design proposes to develop products and services by human needs. Within the contemporary principles of this activity are the dimensions of sustainable development, innovation and social welfare. Sustainable development has concepts from several disciplines and human knowledge. Thus, this article aims to systematize the concept of Design for Sustainability, highlighting its interdisciplinary. Thereby, was carried out a literature research in which the information collected were organized in a conceptual map.
\end{abstract}

Keywords: Design; Sustainable Development; Interdisciplinary.

\section{Introdução}

A interdisciplinaridade se apresenta desde o início na história do Desenvolvimento Sustentável em que há uma variedade de conceitos provenientes de diversas disciplinas. O Design contemporâneo se apresenta cada vez mais implicado com os conceitos de Desenvolvimento Sustentável, inovação e bem-estar social, principalmente diante as demandas da sociedade e do mercado. A análise e o 
design do ciclo de vida do sistema-produto são primordiais em qualquer desenvolvimento de projeto de produto ou serviço.

Com o intuito de sistematizar os conceitos utilizados no campo do Design Sustentável, demonstrar-se-á a interdisciplinaridade da Sustentabilidade no âmbito do Design como atividade profissional criativa. Para tanto, realizou-se pesquisa bibliográfica e sistematização de informações, visando à contribuição para essa prática de projeto.

Inicialmente, podem ser listados os conceitos necessários para o domínio do design para a sustentabilidade, a saber: Desenvolvimento Sustentável; Economia Verde; Ecodesign/Ecoconcepção; Ecoeficiência; Consumo Sustentável; Impacto Ambiental; Ecologia Industrial; Educação Ambiental; Interdependência de produtos e serviços. Esses e outros conceitos e princípios continuam a surgir diante a complexidade do tema e dos desafios socioeconômicos e ambientais impostos aos designers.

Ressalta-se que a interdisciplinaridade, de acordo com Fortes $(2012$, p. 1), "não anula as disciplinas, mas pede que as mesmas dialoguem entre si numa perspectiva educacional em busca de inovação".

Portanto, foram pesquisados conceitos, definições e princípios de relevantes autores e sistematizados os mesmos em um mapa conceitual. Ressalta-se que este é um trabalho que busca a continuidade pela própria complexidade do tema.

\section{Desenvolvimento Sustentável e Economia Verde}

O conceito de desenvolvimento sustentável aparece pela primeira vez em 1987. O mesmo foi definido pela Comissão Mundial para o Ambiente pela ONU, sob direção de Gro Harlem Brundtland. A comissão de Brundtland definiu o Desenvolvimento Sustentável como "aquele que satisfaz as necessidades do presente sem comprometer a capacidade das futuras gerações de satisfazer suas próprias necessidades". (BRIAN, 2008, p.20).

Desenvolvimento para Sachs $(2004$, p.30) é um conceito fugidio e em evolução que teve início de sua reflexão nos anos 40 no contexto da reconstrução da periferia da Europa devastada no pós-guerra. 0 trabalho desta geração de economistas do desenvolvimento foi inspirado na cultura econômica dominante da época que priorizava o pleno emprego, a importância do estado de bem-estar, a necessidade do planejamento e a intervenção do estado na economia, minimizando a insensibilidade social dos mercados. Este autor utiliza a metáfora do arquipélago de empresas modernas com alta produtividade de trabalho que está imerso no oceano de baixa produtividade que forma o tecido intersticial do sistema econômico. "A maior parte do PIB vem do arquipélago. A maior parte das pessoas [nada] no oceano tentando sobreviver". (SACHS, 2004, p.31).

O conceito de Desenvolvimento Sustentável vem sendo refinado ao longo das décadas que separam a Conferência das Nações Unidas sobre o Meio Ambiente, em 1972, ocorrida em Estocolmo e a Rio+20, em 2012, no Rio de Janeiro. Evoluções epistemológicas em que novos conceitos surgem, como o da Economia Verde que prioriza a

erradicação da pobreza, segurança alimentar, um sólido gerenciamento de recursos hídricos, acesso universal a serviços de energia moderna, cidades sustentáveis, gerenciamento de oceanos e melhorando a resistência e a preparação para desastres, assim como a saúde pública, desenvolvimento de recursos humanos e crescimento sustentado, inclusivo e igualitário que gera empregos, incluindo para jovens. (ONU, 2012, p.6).

A partir das crises alimentar, climática e econômica vivenciadas pela humanidade nos últimos anos surge o conceito de Economia Verde como um paradigma alternativo que oferece a promessa de crescimento juntamente com a proteção dos ecossistemas, contribuindo para a redução da pobreza. $O$ conceito de Economia Verde, conforme a Rio+20, "concentra-se principalmente na interseç̧ão entre o ambiente e a economia". E de acordo com a UNEP (2012) "resulta em bem-estar humano e equidade social, reduzindo significativamente os riscos ambientais e a escassez ecológica".

O desenvolvimento sustentável, para Sachs 
obedece ao duplo imperativo ético da solidariedade com as gerações presentes e futuras, e exige a explicitação de critérios de sustentabilidades social e ambiental e de viabilidade econômica. (2004, p.36)

A sustentabilidade pode ser uma ação estratégica para a preservação do ambiente, da cultura e da dignidade social das gerações. A partir dos pilares do Desenvolvimento Sustentável - o ambiental, o social e o econômico - e das discussões de ordem mundial sobre novos paradigmas de consumo e comportamento ressalta-se as mudanças culturais que precisam ocorrer a curto, médio e longo prazo para que se alcance a qualidade de vida almejada pela maioria da população do planeta que vive abaixo da linha da miséria. Nesse ponto, Sachs (2004, pp.38-42) menciona a inclusão justa que deve ocorrer por meio de um desenvolvimento includente em que todos os cidadãos devem ter igualdade de condições e é fundamentado no trabalho decente para todos.

A sustentabilidade, em todas as suas dimensões, deve ser um objetivo a ser alcançado. Manzini e Vezzoli (2002, p. 28), descrevem que para ser sustentável é preciso responder a requisitos como: utilizar recursos renováveis; otimizar o emprego de recursos não renováveis; não acumular lixo; e, como mencionado por Holmberg (1995), que as sociedades ricas permaneçam nos limites de seus espaços ambientais para que as pobres possam gozar de seu ambiente o qual efetivamente têm direito. Casabianca (1998, p.40), menciona ainda o papel do Estado que, entre outras coisas, é o de formular políticas de incentivos à produção limpa e a prevenção de contaminação.

Considerando tais requisitos, percebem-se como as sociedades industriais e os Estados mais desenvolvidos estão distantes do objetivo da sustentabilidade pelo uso insensato de recursos renováveis e não renováveis e pelo não respeito às sociedades subdesenvolvidas ou em desenvolvimento.

Desse modo, a seguir serão descritos alguns conceitos e princípios inerentes ao conceito de desenvolvimento sustentável e que são premissas básicas para a compreensão do design para a sustentabilidade como conceito interdisciplinar.

\section{Biocompatibilidade, Impacto Ambiental e Ecologia Industrial}

O objetivo da biocompatibilidade, conforme Manzini e Vezzoli (2002, p. 33), é a realização de um sistema de produção e consumo baseado em recursos renováveis e que sua retirada não ultrapasse os limites da produtividade dos sistemas naturais e que sua eliminação no ecossistema seja totalmente biodegradável, separados de acordo com sua capacidade de renaturalização. De fato, somente os produtos e serviços efetivamente compatíveis com recursos renováveis existentes podem ser realizados no quadro da biocompatibilidade.

O Impacto Ambiental é qualquer alteração das propriedades físicas, químicas e biológicas do meio ambiente, causada por qualquer forma de material ou energia resultante de atividades humanas que, direta ou indiretamente afetam a saúde, a segurança e o bem estar da população, as atividades sociais e econômicas, as condições estéticas e sanitárias do meio ambiente e a qualidade dos recursos ambientais. (CONAMA, 1996).

A Ecologia Industrial considera um sistema produtivo um subsistema da biosfera (litosfera, hidrosfera e atmosfera). Uma organização particular de fluxos de matéria, de energia e informação. Neste sentido, são levados em consideração dois conceitos-chave: o metabolismo industrial que se fundamenta na conservação da matéria. Baseando-se que a quantidade de matéria que transita na biosfera mantém-se constante, não desaparecendo após o seu descarte apenas perdendo o seu valor econômico; a desmaterialização da produção que se fundamenta na redução quantitativa da matéria, aumentando a produtividade dos recursos. (POLIS ESTUDOS, 1998).

Desta forma, torna-se importante conhecer também os conceitos das principais áreas que a Ecologia abrange, como:

- a Biosfera é a camada de vida que circunda o planeta, a soma de todos os ecossistemas da Terra. Constitui-se no maior sistema biológico e o que mais se aproxima da autossuficiência. 
Inclui todos os organismos vivos da Terra que interagem entre si e com o ambiente físico como um todo, a fim de manter um equilíbrio autoajustável. (ODUM, 1985).

- o Ecossistema é o conjunto de elementos bióticos (seres vivos) e abióticos (fatores diversos do ambiente) de uma determinada área, que trocam entre si influências notáveis, com a transferência de matéria e energia, visando um equilíbrio estável (MARCONDES; SOARES, 1991). Portanto, o homem é considerado como parte do meio ambiente e dos sistemas humanos.

- a Comunidade é o conjunto de organismos de espécies distintas que convivem em uma mesma área.

Para Capra (1996, p.218)

Naturalmente, há muitas diferenças entre ecossistemas e comunidades humanas. Nos ecossistemas não existe autopercepção, nem linguagem, nem consciência e nem cultura; portanto, neles não há justiça nem democracia; mas também não há cobiça nem desonestidade. Não podemos aprender algo sobre valores e fraquezas humanas a partir de ecossistemas. Mas o que podemos aprender, e devemos aprender com eles é como viver de maneira sustentável. Durante mais de três bilhões de anos de evolução, os ecossistemas do planeta têm se organizado de maneiras sutis e complexas, a fim de maximizar a sustentabilidade. Essa sabedoria da natureza é a essência da eco-alfabetização.

Cada comunidade é composta por populações.

- a População, é um conjunto de organismos da mesma espécie convivendo em uma área comum e mantendo ou não certo grau de isolamento em relação a grupos de outras regiões (MARCONDES; SOARES, 1991).

A não interferência tem como objetivo realizar um sistema fechado de produção e consumo, reutilizando e reciclando todos os materiais que formariam tecnociclos (ciclos tecnológicos) com a tendência a autonomia em relação aos ciclos naturais. Esse objetivo ainda é impossível de ser atingido nem mesmo de forma teórica, pois é impraticável que os tecnociclos não interfiram em nada na biosfera. Ou seja, sempre, e mesmo de modo insignificante, há o impacto ambiental em sistemas de produção e consumo.

Partindo-se da tecnologia e da cultura têm-se os percursos para a sustentabilidade ambiental, apontados por Manzini e Vezzoli (2002, p.41), que podem ser subdivididos em eficiência, suficiência e eficácia. A área da eficiência parte dos produtos denominados limpos e recicláveis que operam no âmbito de uma ecologia industrial e caracterizados pelos tecnociclos. A área de suficiência parte dos produtos biológicos e biodegradáveis e no âmbito de uma ecologia industrial está caracterizada pelos biociclos. Os percursos na área da eficácia partem dos produtos e serviços ecoeficientes e se colocam no âmbito da ecologia industrial fortemente desmaterializada.

Na figura 1, percebem-se, visualmente, tais percursos para a sustentabilidade ambiental em que a partir das combinações entre as mudanças culturais (dimensão sociocultural) e tecnológicas (dimensão técnica) novas possíveis soluções sustentáveis podem ser caracterizadas.

Este plano definido pelos eixos - mudança tecnológica e mudança cultural - indica três ordens de articulações, a saber: como avaliar quando as soluções podem ser consideradas sustentáveis; quais são os significados e as implicações das diversas combinações entre inovação técnica e inovação sociocultural; e quais são os percursos idealmente praticáveis para se alcançar a sustentabilidade. (MANZINI; VEZZOLI, 2002, p.41)

Figura 1 - Percursos para a sustentabilidade e as áreas da suficiência, eficiência e eficácia. 


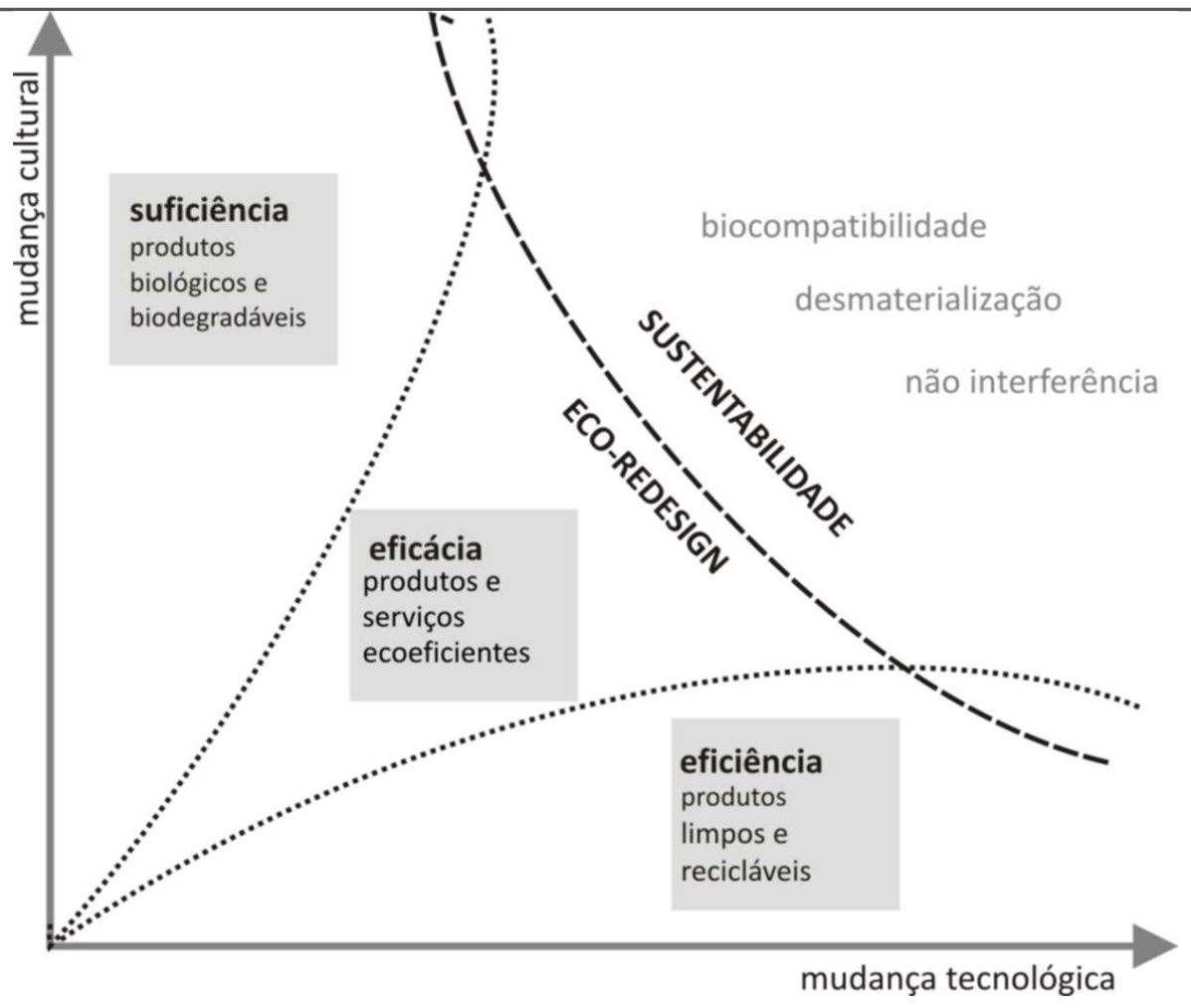

Fonte: baseado em Manzini e Vezzoli (2002, pp. 36-41).

\section{Ecoeficiência, Ecoconcepção e Ecodesign}

A Ecoeficiência é o conceito difundido para prestação de serviços com desempenho econômico e ambientalmente correto, conforme o Conselho Empresarial Mundial para o Desenvolvimento Sustentável. É para Larica (2003), o aumento da produtividade e da rentabilidade nas organizações a partir da redução dos impactos ambientais.

O Ecodesign que teve sua primeira definição dada por Victor Papaneck trabalha em prol de diminuir o impacto do ser humano no planeta. Para Kazazian $(2005$, p.36), o ecodesign faz parte de um processo que busca tornar a economia mais "leve". Chamado também de ecoconcepção que trata da redução do impacto de um produto no meio, conservando suas qualidades de uso (funcionalidade, desempenho) para melhorar a qualidade de vida dos usuários. "Segundo essa abordagem, o meio ambiente é tão importante quanto à exequibilidade técnica, o controle dos custos e a demanda do mercado". O ecodesign, como uma abordagem global, exige uma nova maneira de conceber, considerando todas as etapas do ciclo de vida de um produto ou serviço. Ressalta-se que em uma ecoconcepção inicia-se um processo cooperativo com uma cadeia de atores em uma abordagem transversal e multidisciplinar.

\section{Gestão Ambiental e Mecanismos de Desenvolvimento Limpo}

A gestão ambiental é utilizada para evitar problemas com o meio ambiente. Tem como objetivo obter o desenvolvimento sustentável e é o principal instrumento para obter um desenvolvimento industrial sustentável, pois está vinculada a normas, as quais envolvem prefeituras, governos estaduais quanto federais. Essas normas delimitam os

“limites aceitáveis de emissão de substâncias poluentes, definem em que condições serão despojados os resíduos, proíbem a utilização de substâncias tóxicas, definem quantidade de água que pode ser utilizada, volume de esgoto que pode ser lançado etc. (DIAS, 2009, p.89).

As normas são obrigatórias para as indústrias e/ou empresas que pretendem trabalhar com um 
Sistema de Gestão Ambiental (SGA) que pode ser definido como um "conjunto de responsabilidades organizacionais, procedimentos, processos e meios que se adotam para a implantação de uma politica ambiental em determinada empresa ou unidade produtiva". O SGA é um método para a empresa manter-se em funcionamento de acordo com as normas estabelecidas. (DIAS, 2009, p.91).

Em qualquer empresa pode-se aplicar a gestão ambiental. As de pequeno porte enfrentaram algumas dificuldades, pois deverão dedicar parte dos recursos humanos e financeiros as normas da ISO 14000.

Segundo Dias (2009) existem diversas razões para uma empresa adotar a gestão ambiental, tais como, interesses econômicos que surgem de estímulos internos e externos. Os estímulos internos estão relacionados ao processo de desenvolvimento e inovação do produto, sendo estes: necessidade de redução de custos. Incremento de qualidade no produto, melhoria da imagem do produto e da empresa, necessidade de inovação, aumento da responsabilidade social, e sensibilização do pessoal interno. Já os estímulos externos estão relacionados à demanda de mercado, a concorrência, poder público e legislação ambiental meio sociocultural, certificações ambientais e fornecedores.

Portanto, a cada dia se torna mais importante à implantação de gestão ambiental ou sustentável nas empresas, pela mudança de mentalidade e de cultura organizacional em relação à reparação de danos ambientais, competitividade empresarial e também pelas exigências dos consumidores.

Em 1989, o termo Produção Mais Limpa $(\mathrm{P}+\mathrm{L})$ foi lançado pela UNEP (United Nations Environment Program) e a DTIE (Divisionof Technology, Industryand Environment). A P+L visa à eficiência das empresas e a competitividade de seus produtos, compatibilizando seus processos produtivos com os recursos naturais e utilizando com eficiência a energia, a água e as matérias-primas.

\section{Educação Ambiental, Ecoeducação e Consumo Sustentável}

A educação, de acordo com Sachs (2004, p. 39), é essencial para o desenvolvimento, pois contribui "para o despertar cultural, a conscientização, a compreensão dos direitos humanos, aumentando a adaptabilidade e o sentido de autonomia", autoconfiança e autoestima. Não pode ser considerada uma panaceia, mas que precisa fazer parte de um conjunto de políticas de desenvolvimento.

A Educação Ambiental é o aprendizado para compreender, apreciar, saber lidar e manter os sistemas ambientais na sua totalidade. Este tema desperta a consciência sobre a reciclagem e a não perda do valor econômico do que é considerado lixo, nos dando condições de aprender como funciona o ambiente e adquirir o conhecimento e a prática do ato de separar o lixo urbano (doméstico e industrial), fazendo com que um determinado material retorne ao seu ciclo de produção, após ter sido utilizado e descartado, para que novamente possa ser transformado em um bem de consumo, economizando energia, preservando recursos naturais e ainda beneficiando socialmente por meio da geração de trabalho e renda.

O Consumo Sustentável deriva da percepção de que se todos consumissem tanto quanto os cidadãos dos países ricos, logo os recursos naturais acabariam. "Uso de serviços e produtos que respondam às necessidades básicas de toda a população e proporcionem melhoria na qualidade de vida, reduzindo ao mesmo tempo o uso dos recursos naturais e de materiais tóxicos, a produção de lixo e emissões de poluição em todo ciclo de vida, sem comprometer as necessidades das futuras gerações" (Comissão de Desenvolvimento Sustentável da ONU).

Para TEIXEIRA (2006, p.152-153) a educação é colocada como instrumento de promoção da inclusão social e integração da economia globalizada como requisito para o desenvolvimento sustentável. Contribui para a sustentabilidade social e formação integradora ao mercado de trabalho.

A Unesco divulga desde 1970, a sobre a necessidade da educação ambiental e diz que

"adquirir conhecimentos, valores, comportamentos e competências praticas necessárias para participar de maneira responsável e eficaz na preservação e na solução dos problemas do meio ambiente e na gestão da qualidade ambiental". (PELTIER E SAPORTA, 2009, p.102).

Interdependência de produtos e serviços 
Para Kazazian (2005, pp.30-37), a interdependência permite o sentido de direção, pois "qualquer fenômeno repercute no conjunto, que, por sua vez, mais ou menos tarde e de forma mais ou menos intensa, acaba repercutindo na fonte do fenômeno". A economia integra a interdependência que por sua vez ministra dois princípios, a saber: o da responsabilidade e o da precaução. O princípio da responsabilidade foi teorizado por Hans Jones, em 1979, ao refletir sobre as consequências de um "agir irresponsável em uma natureza explorada e negada". Os indivíduos e a coletividade devem assumir as consequências de seus atos. Um exemplo que dificulta esta responsabilidade são os mercados de cotas de $\mathrm{CO}_{2}$ que compram ou vendem autorizações de emissão. É uma prática que pode ser chamada de "permissão para poluir" que se por um lado houve uma redução de $50 \%$ nas emissões de óxido de enxofre, por outro se constituem em um paliativo aos modestos objetivos determinados pelo Protocolo de Quioto que não devem substituir os acordos internacionais. (KAZAZIAN, 2005, p.32). O princípio da precaução incita à prudência e ao bom senso. Kazazian (2005, p.33), descreve que a precaução consiste na ampliação da percepção do desenvolvimento à complexidade dos sistemas que regem a natureza e questionam nossas certezas. Este princípio deve ser aplicado às diversas formas de estruturas (políticas, institucionais ou industriais), pressupõe debate público, embora a concordância entre atores responsáveis ainda esteja longe de se alcançar. A exemplo disso tem-se os debates sobre os alimentos provenientes de organismos geneticamente modificados (OGM) pela pouca informação sobre as consequências de seu consumo.

Uma empresa, assim como um produto devem ser vistos como células ativas em meio a um conjunto de relações com o meio ambiente, sendo que a empresa gera poluição em sítios de produção geograficamente delimitados e o produto pode ser visto como um poluidor nômade. Um exemplo é a "Grande Ilha de Lixo do Pacífico, descoberta, em 1997, [pelo capitão] Charles Moore, é um dos

principais ícones da depredação provocada pelo plástico nos oceanos", conforme a Rio+20 (2012).

\section{Capitalismo Natural}

Hawken et al (2007, pp.3-9), define o capital como a riqueza acumulada na forma de investimentos, fábricas e equipamentos. Menciona que uma economia requer os tipos de capital, a saber: o capital humano; o capital financeiro, o capital manufaturado e o capital natural. Este último é constituído de recursos, sistemas vivos e serviços do ecossistema. Deste modo, o Capitalismo Natural procura dar importância aos sistemas vivos e reconhece a interdependência entre produção e uso de capital produzido pelo homem por um lado, e a preservação e o fornecimento de capital natural, por outro. Este conceito se alicerça em uma mentalidade e em uma escala de valores diferente das do capitalismo convencional.

O Capitalismo Natural tem como pressupostos básicos os itens a seguir: o meio ambiente é um invólucro que contém, abastece e sustenta o conjunto da economia. Não pode ser tratado com fator de produção sem importância; os fatores limitadores do desenvolvimento econômico futuro são a disponibilidade do capital natural; deve-se alcançar a economia sustentável por meio da concepção e projeto melhores executados dos sistemas de negócios e de crescimento populacional e dos padrões dissipadores de consumo; o progresso econômico futuro tem melhores condições de ocorrer em sistemas de produção e distribuição mais democráticos baseados no mercado; o bem-estar humano é mais favorecido pela melhoria da qualidade e do fluxo da prestação de serviços desejáveis do que o aumento de fluxo financeiro; a sustentabilidade econômica e ambiental depende da superação das desigualdades de renda; sistemas de governos democráticos que se apoiam nas necessidades das pessoas e não das empresas. (HAWKEN et al, 2007, pp.8-9).

\section{Economia Solidária e Erradicação da pobreza}

A Economia Solidária se desenvolve por meio de princípios que contrariam a lógica do capitalismo, pois considera o trabalho decente e em rede de produção, de consumo e de troca. Funciona em paralelo com o Comércio Justo que é uma forma ética de comercialização com justiça 
social, transparência, preço justo, empoderamento dos participantes, solidariedade e sustentabilidade. (SANTOS, 2005, p. 71). Um de seus objetivos é o da erradicação da pobreza que também tem sido abordada nas discussões contemporâneas do desenvolvimento sustentável, sendo um dos propósitos da economia verde e do capitalismo natural.

\section{Design para a sustentabilidade e a sistematização dos conteúdos interdisciplinares}

Para Manzini (2003), o Design para a Sustentabilidade considera questões ambientais e o estudo do ciclo de vida no Design de Produto. Neste contexto, procura-se equilibrar o sistema produtivo com as necessidades do bem estar social, otimizando os processos e a vida útil dos produtos, tendo como ponto de convergência a redução dos impactos ambientais.

Para Vezzoli (2010, p.45) em um sentido mais amplo pode ser definido como "uma prática de design, educação e pesquisa que, de alguma maneira, contribui para o desenvolvimento sustentável".

No desenvolvimento de produtos sustentáveis tem-se a problemática da duração desses produtos no meio desde a sua concepção até o seu descarte ou reaproveitamento/reciclagem e a questão da gestão de todo esse processo. A durabilidade, conforme Kazazian $(2005$, p.45) supõe uma gestão da obsolescência que pode ser objetiva (motivada pelos avanços técnicos) ou subjetiva (motivada pela aparência ditada pela moda). Aumentar com qualidade a duração da vida de um produto é uma estratégia oportuna para uma empresa.

O produto visto como sistema é um ponto crucial para se compreender, estudar e analisar o seu ciclo de vida. O produto "é interpretado em relação aos fluxos - de matéria, energia e emissão das atividades que o acompanham em toda a sua vida". (MANZINI; VEZZOLI, 2002, p.91). o ciclo de vida de um produto pode ser compreendido como um conjunto de processos reagrupados de acordo com Manzini e Vezzoli (2002, p.91) em: pré-produção; produção; distribuição; uso; descarte.

$\mathrm{Na}$ figura 2 apresentam-se diversos conceitos e princípios advindos de outros conhecimentos e os seus inter-relacionamentos.

Figura 2 - Breves conceitozs interdisciplinares do Design para a Sustentabilidade.

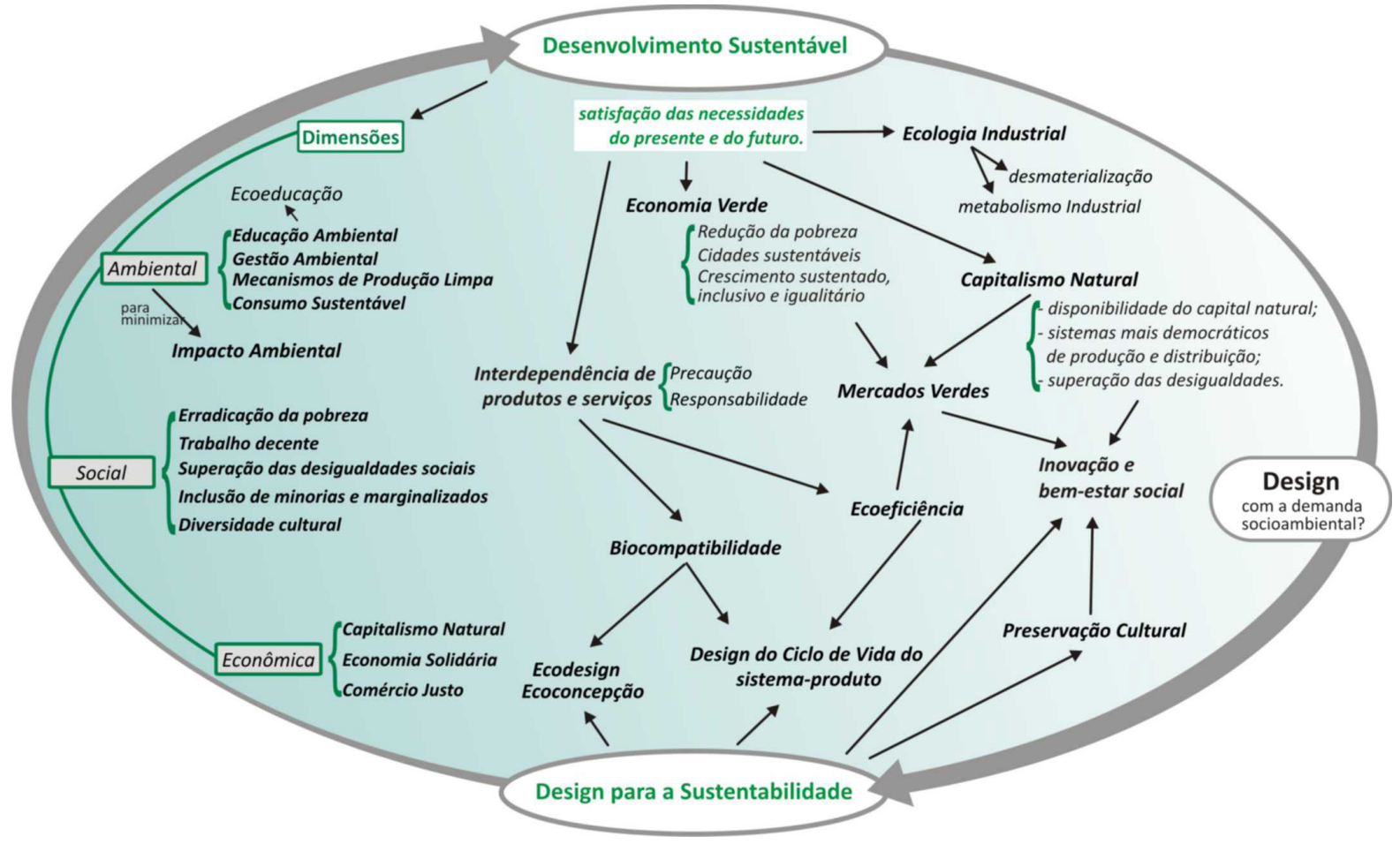

Fonte: própria, 2012.

Tais conceitos interdisciplinares foram sistematizados em um mapa conceitual que os direcionam 
para as dimensões ambientais, econômicas e sociais e para a interdependência de produtos e serviços. $O$ design está inserido nesse contexto juntamente com a demanda socioambiental em que nasce a necessidade do desenvolvimento de produtos sustentáveis e de uma economia do desenvolvimento alternativo.

\section{Conclusões}

Este artigo se propôs a apresentar alguns conceitos relevantes para o entendimento do design para a sustentabilidade, demonstrando sua interdisciplinaridade, sem a pretensão de estabelecer limites em um conceito ainda em construção.

A investigação se pautou em uma pesquisa bibliográfica que auxiliou na construção do mapa conceitual, evidenciando seus inter-relacionamentos. Nesse mapa, têm-se alguns conceitos que levam a reflexão sobre o design para o desenvolvimento sustentável em que a inovação e o bem-estar social devem ser considerados, equitativa e juntamente, à dimensão econômica no desenvolvimento de um produto. Este irá passar por um ciclo produtivo que em todas as suas etapas gasta energia, gera resíduos e emite poluição, e, não apenas, as questões ambientais e econômicas devem ser contempladas, mas também as implicações socioculturais.

\section{Referências}

ARAÚJO, M. Produtos Ecológicos para uma sociedade sustentável. São Paulo: O Estado de São Paulo, 2001.

BRIAN, Edwards. 0 guia básico para a sustentabilidade. Barcelona: Gráficas 92, 2008.

CASABIANCA, Alexandra Terán. Sustentabilidade Ambiental. Um desafio para a indústria. Revista Gerenciamento Ambiental - Ano 01 - no 01. Abril/1998.

CAPRA, F. A Teia da Vida - uma nova compreensão científica dos sistemas vivos. Trad. N. R. Eichemberg. São Paulo: Cultrix, 1996.

Comissão de Desenvolvimento Sustentável da Organização das Nações Unidas - ONU. A ONU e o Meio Ambiente. Disponível em: <http://www.onu.org.br/a-onu-em-acao/a-onu-e-o-meio-ambiente/> Acesso em: 22/06/2012.

CONSELHO NACIONAL DO MEIO AMBIENTE - CONAMA. GESTÃO DE RESÍDUOS E PRODUTOS PERIGOSOS. RESOLUÇÃO CONAMA no 23, de 12 de dezembro de 1996. Publicada no DOU no 13, de 20 de janeiro de 1997, Seção 1, páginas 1116-1124. Disponível em: <http://www.mma.gov.br/port/ conama/legiabre.cfm?codlegi=222>. Acesso em: 22/06/2012.

DIAS, Reinaldo. Gestão ambiental: responsabilidade e sustentabilidade. São Paulo: Atlas, 2009.

FORTES, C.c. Interdisciplinaridade: Origem, Conceito e Valor.

Disponível em: <http://www3.mg.senac.br/NR/rdonlyres/ eh3tcog37oi43nz654g3dswloqyejkbfuxkjpbgehjepnlzyl4r3inoxahewtpql7drvx7t5hhxkic/ Interdisciplinaridade.pdf>. Acesso em: 27/06/2012.

FUNDO NACIONAL DO MEIO AMBIENTE. Disponível em: $<$ http://www.mma.gov.br>. Acesso em: 23/02/2007.

HAWKEN, P.; LOVINS, A.; LOVINS, H. Capitalismo Natural: criando a próxima revolução industrial. Trad. Luiz A. de Araújo, Maria Luiza Felizardo. São Paulo: Cultrix, 2007.

KAZAZIAN, T. Haverá a idade das coisas leves: design e desenvolvimento sustentável, São Paulo: Ed. 
SENAC, 2005.

LARICA, N. J. Design de Transportes: arte em função da mobilidade. Rio de Janeiro: 2AB, 2033.

LAN, F. O que são Negócios Sustentáveis? Organizadores: Rocha, M.T., Dorresteijn, H. \& Gontijo M.J. Empreendedorismo em Negócios Sustentáveis - plano de negócios como ferramenta de desenvolvimento, São Paulo: Peirópolis; Brasília, DF: IEB - Instituto Internacional de Educação do Brasil, 2005.

MAFRA, M. O Meio Ambiente em Londrina - diferencial de qualidade para o desenvolvimento regional, CODEL - Companhia de Desenvolvimento de Londrina da Prefeitura Municipal de Londrina, 2005.

MANZINI, E.; VEZZOLI, C. O desenvolvimento de produtos sustentáveis. Trad. Astrid de Carvalho. São Paulo: Ed. USP, 2002.

Design para a inovação social e sustentabilidade - comunidades criativas, organizações colaborativas e novas redes projetuais. Rio de Janeiro: E-papers, 2008.

MARCONDES, A.C.; SOARES, P.A.T. Curso Básico de Educação Ambiental. Ed.

Scipione, 1991.

ODUM, E.P. Ecologia; trad. Cristopher J. Tribe - Ed. Guanabara (RJ), 1985.

ORGANIZAÇÃO DAS NAÇÕES UNIDAS (ONU). O FUTURO QUE QUEREMOS. Conferência das Nações Unidas sobre o Desenvolvimento Sustentável - Rio+20, Rascunho zero do documento final, 10 de janeiro de 2012. Disponível em: <http://www.onu.org.br-/rio20/img/2012/01/OFuturoqueQueremos rascunho_zero.pdf>. Acesso em: 21/06/2012.

PANAYOTOU, Theodore. Mercados Verdes - a economia do desenvolvimento alternativo, RJ: Ed. Nórdica, 1994.

PAPANEK, Victor. Design for the real world. s.I.: Thames and Hudson, 1985.

REDE BRASILEIRA DE EDUCAÇÃO AMBIENTAL. Disponível em: <http://www.rebea.org.br>. Acesso em: 22/06/2012.

RIO+20 - Conferência das Nações Unidas sobre o Desenvolvimento Sustentável. Economia Verde - A economia verde no contexto do desenvolvimento sustentável e a erradicação da pobreza. Disponível em: <http://www.rio20.info/2012/economia-verde>. Acesso em: 25/06/2012.

RIO+20 - Conferência das Nações Unidas sobre o Desenvolvimento Sustentável. Países priorizam eliminação do lixo plástico nos oceanos na Rio+20. Disponível em: <http://www.rio20.gov.br/ sala_de_imprensa/-paises-priorizam-eliminacao-do-lixo-plastico-nos-oceanos-na-rio-20>. Acesso em: 25/06/2012.

SACHS, Ignacy, Desenvolvimento: includente, sustentável, sustentado. Rio de Janeiro: Garamond, 2004.

SANTOS, G. F. dos, Negócios Sustentáveis e Desenvolvimento: Uma relação de causa e efeito, organizado por Rocha, M.T., Dorresteijn, H. \& Gontijo M.J. Empreendedorismo em Negócios Sustentáveis: plano de negócios como ferramenta de desenvolvimento, São Paulo: Peirópolis; Brasília, DF: IEB:Instituto Internacional de Educação do Brasil, 2005.

SILVA, L.V. M. de, FARIA, I.F. de, DIAS, A.L.A. Design e Produtos Florestais Não-Madeireiros: 
Cavalcante, Ana Luisa B. L.; Preto, Seila Cibele Sitta;Pereira, Francisco A. F.; Figueiredo, Luiz Fernando G. de

Sustentabilidade Comunitária em Silves-Am, V Encontro Nacional da Anppas, Florianópolis, SC, 4 a 7 de outubro de 2010. Disponível em: <http://www.anppas.org.br/encontro5/cd/artigos/GT7-40242920100906011410.pdf> Acesso em 07 fev 2011.

SILVEIRA, Antônio. Programa Ambiental: A última Arca de Noé - Desenvolvimento Sustentável. São Paulo: Blücher, 2000.

SPINK, Peter; CAMAROTTI, Ilka, (Org) Redução da Pobreza e Dinâmicas Locais. RJ: Editora FGV, 2a Ed. 2000.

PELTIER, F.; SAPORTA, H. Design sustentável - caminhos virtuosos. São Paulo: Senac, 2009

TEIXEIRA, Cristina. Educação e desenvolvimento sustentável na agenda 21 brasileira. Inter-Ação: Rev. Fac. Educ. UFG, 33 (1): 31-48, jan./jun. 2008

ULMANN, Christian. Para um design solidário e sustentável. Disponível em: <http://www. designemdia.com.br/opiniao/read.php?id=35>. Acesso em: 11 dez 2009.

UNEP - United Nations Environment Programme - UN Conference on Trade and Development. The Transition to a Green Economy: Benefits, Challenges and Risks from a Sustainable Development Perspective. Disponível em: < http://www.uncsd2012.org/rio20/content/documents/Green\%20Economy_ full\%20report\%20final\%20for\%20posting\%20clean.pdf>. Acesso em: 25/06/2012.

VEZZOLI, Carlo. Design de sistema para sustentabilidade: teoria, métodos e ferramentas para o design sustentável de "sistema de satisfação". Salvador: EDUFBA, 2010. 
Design para a Sustentabilidade - um conceito interdisciplinar em construção 